\title{
县域尺度下中国人口老龄化的空间格局 与区域差异
}

\author{
王录仓 ${ }^{1}$, 武荣伟 ${ }^{2,3}$, 刘海猛 ${ }^{4,3}$, 周 鹏 ${ }^{1}$, 康江江 ${ }^{5}$ \\ (1. 西北师范大学地理与环境科学学院, 兰州 $730070 ; 2$. 中国科学院新疆生态与地理研究所, 乌鲁木齐 830011 ; \\ 3. 中国科学院大学, 北京 100049 ; 4. 中国科学院地理科学与资源研究所, 北京 100101; \\ 5. 河南大学环境与规划学院, 河南开封 475004)
}

\begin{abstract}
摘 要: 2000 年以来, 中国的老龄化进程加快, 人口老龄化已经成为中国社会经济发展必须面对的新常态与核心问 题之一。本文从县域尺度出发, 基于 2000 和 2010 年的人口普查数据, 应用标准差椭圆、地理探测器等方法, 分析了 10 年间中国 2283 个县域单元人口老龄化的空间分布、区域差异及其影响因素。结果表明: (1)人口老龄化空间分布 模式多样, 胡焕庸线西北半壁以均质化、轴带特征为主; 而胡焕庸线东南半壁则呈现出核心一外围的分布特征。 (2)2000-2010年间, 人口老龄化均值从 $6.7 \%$ 增至 $8.7 \%$, 表明中国县域全面进人老年型社会, 步人老年型的县域多集 中于内陆、东北地区、丝绸之路经济带沿线区; 10 年间人口老龄化总体空间格局较为稳定,但人口老龄化的变动趋 势差异显著。(3人口老龄化在 “胡焕庸线”两侧、不同地域类型间、城乡间、民族自治地区与非民族自治地区间、贫 困与非贫困地区间存在差异, 且差异变动的方向并不一致。(4)影响人口老龄化的核心因素为各区域往期人口年龄 结构、步人老年序列人口比重、人口流出的比例等。
\end{abstract}

关 键 词: 人口老龄化; 县域尺度;空间格局; 区域差异; 中国

\section{1 引言}

“ 100 亿人在地球上如何生存和分布”被认为是 21 世纪地理科学的 11 个重大战略方向之一(National Research Council, 2011)。人口年龄结构是人口 的重要属性, 人口老龄化的空间分布研究是其中的 一个重要方面。自 1970 年代中国实行了严格的“计 划生育”政策以来, 在人口总量得到有效控制的同 时, 人口老龄化速度加快。1981-2000年的 20年间, 中国老年人口 (65 岁及以上的人口)的比重从 $4.9 \%$ 升至 7.0\%, 而欧美国家经历这一历程大约用了 45 120 年(谢安, 2004)。从 2000 年开始, 中国全面进人 老龄化社会, 2000-2010年间, 中国老年人口年均增 长率高达 3.5\%(于涛方, 2013)。在社会转型和空间 重构背景下, 中国人口老龄化日趋复杂(高晓路等, 2015)。面对人口老龄化态势日趋严重这一新常
态, 党的十八大报告提出, 应积极应对人口老龄化, 大力发展老龄服务事业和产业。同时,适度调整了 人口政策, 2013 年 10 月,十八届三中全会决定启动 实施一方是独生子女的夫妇可生育 2 个孩子的政 策。2015 年 12 月, 十八届五中全会又一致通过普 遍二孩政策, 以促进人口长期均衡发展。中国人口 老龄化已经成为政府、学者、媒体、大众普遍关注的 焦点问题(高晓路等, 2015)。

然而, 由于中国不同区域自然条件和社会经济 条件差异巨大, 人口老龄化在空间分布上存在显著 的非均衡现象(刘华军等, 2014)。从19世纪后期开 始, 欧美发达国家相继进人了老龄化社会, 故西方 发达国家对老年人口空间分布问题研究较早(柴彦 威等, 2006), 如美国学者以州为基本研究单元, 对 美国的老龄化率空间分布进行研究, 发现中西部、 东北部各州及佛罗里达州人口老龄化率显著高于

收稿日期: 2016-01; 修订日期: 2016-05。

基金项目:国家自然科学基金项目(41261042) [Foundation: National Natural Science Foundation of China, No.41261042]。

作者简介:王录仓(1967-), 男,甘肃天水人,教授,博导,主要从事城乡发展与规划研究,E-mail: wanglc007@nwnu.edu.cn。

引用格式: 王录仓, 武荣伟, 刘海猛, 等. 2016. 县域尺度下中国人口老龄化的空间格局与区域差异[J]. 地理科学进展, 35(8): 921-931. [Wang L C, Wu R W, Liu H M, et al. 2016. Spatial patterns and regional differences of population ageing in China based on the county scale[J]. Progress in Geography, 35(8): 921-931.]. DOI: 10.18306/dlkxjz.2016.08.001 
其他区域(McCarthy, 1983)。近年来发展中国家也 开始重视人口老龄化区域差异的研究, Káčerová等 (2012)对捷克和斯洛伐克 1996 和 2009 年的人口老 龄化进行了对比, 并在地区尺度(district level)上对 两国的人口老龄化程度进行了聚类分析。自 2000 年中国逐渐进人老龄化社会以来, 人口老龄化的地 区差异便逐渐成为研究热点, 成果丰富, 内容充 实。对于人口老龄化区域差异的研究主要集中在 以下 4 个方面: 国际间差异(单良等, 2013; 王志宝 等, 2015)、省际差异 (李日邦等, 1999; 袁俊等, 2007)、省域内差异(张开洲等, 2014)和大都市市区 人口老龄化空间格局 (林琳等, 2007; 李扬等, 2011)。综观已有研究发现, 多数文献基于全国尺 度, 探讨人口老龄化的演变趋势及其区域差异; 在 区域差异测度方面, 以省为基本单元, 探讨东、中、 西三大地区之间的差异及其变动, 并分析了人口老 龄化的影响因素。由于空间尺度较大, 忽略了省域 内人口老龄化空间分布的非均质性, 且很难清晰刻 画和展现中国人口老龄化空间格局的细节特征与 规律; 个别研究案例虽然对省内进行了细化研究, 但由于研究单元所限, 又无法一览全国格局的宏观 规律。当前, 及时、科学地应对人口老龄化成为各 地区无法回避的问题。然而, 人口老龄化存在的巨 大区域差异对政策的制定与实施提出了挑战, 对中 国人口老龄化区域差异必须有清晰的认识。因此, 本文从县域尺度出发, 采用“五普”和“六普”分县人 口数据资料, 综合应用数理统计方法和空间分析方 法, 对中国 2000-2010年间人口老龄化的空间分布、 区域差异及其影响因素进行系统分析, 以期为国家 和地方政府应对人口老龄化问题, 提供有针对性的 决策支持和科学依据。

\section{2 数据与方法}

\section{1 数据来源}

本文主要数据来源于 $《 2000$ 年人口普查分县资 料》和《中国人口普查分县资料》(2010), 从中提取总 人口、老年人口、年龄结构等属性数据, 同时将 2000 年的分县数据统一于 2010 年的行政区划体系中, 地 级市市辖区作为一个行政单元来处理。同时将新 成立的县级行政区合并到原行政区中, 这样共得到 2283 个县域研究单元。衡量老龄化程度指标较多, 但是学者们主要采用老年人口比重(65 岁以上人口 数占总人口的比重)这一指标。该指标是反映地区
人口老龄化现象最直接的测度指标, 是体现人口老 龄化程度及水平的重要标志。因此, 本文选取老年 人口比重作为老龄化程度的测度指标。

\section{2 研究方法}

\subsection{1 标准差椭圆分析方法}

标准差椭圆(Standard Deviational Ellipse, SDE) 是空间统计方法中能够精确揭示要素空间分布多 方面特征的方法,用于揭示地理要素的空间分布特 征(中心性、展布性、方向性、空间形态等)(Yuill, 1971; 赵作权, 2009), SDE 主要参数的计算公式 如下:

$$
\begin{aligned}
& \text { 平均中心: } \quad \bar{X}_{w}=\frac{\sum_{i=1}^{n} w_{i} x_{i}}{\sum_{i=1}^{n} w_{i}} \\
& \bar{Y}_{w}=\frac{\sum_{i=1}^{n} w_{i} y_{i}}{\sum_{i=1}^{n} w_{i}} \\
& \text { 旋转角: } \quad \tan \theta=(A+B) / C \\
& A=\left(\sum_{i=1}^{n} \bar{x}_{i}^{2}-\sum_{i=1}^{n} \bar{y}_{i}^{2}\right) \\
& B=\sqrt{\left(\sum_{i=1}^{n} \bar{x}_{i}^{2}-\sum_{i=1}^{n} \bar{y}_{i}^{2}\right)^{2}+4\left(\sum_{i=1}^{n} \bar{x}_{i} \bar{y}_{i}\right)} \\
& C=2\left(\sum_{i=1}^{n} \bar{x}_{i} \bar{y}_{i}\right)
\end{aligned}
$$

$x$ 轴标准差:

$$
\sigma_{x}=\sqrt{\frac{\sum_{i=1}^{n}\left(\bar{x}_{i} \cos \theta-\bar{y}_{i} \sin \theta\right)^{2}}{n}}
$$

$y$ 轴标准差:

$$
\sigma_{y}=\sqrt{\frac{\sum_{i=1}^{n}\left(\bar{x}_{i} \sin \theta-\bar{y}_{i} \cos \theta\right)^{2}}{n}}
$$

式中: $\left(x_{i}, y_{i}\right)$ 表示研究对象 $i(i=1,2,3, \ldots, n)$ 的坐标; $w_{i}$ 表示权重; $\left(\bar{X}_{w}, \bar{Y}_{w}\right)$ 表示加权平均中心 ; $\theta$ 表示 椭圆的方位角; $\bar{x}_{i} 、 \bar{y}_{i}$ 分别表示各研究对象区位到 平均中心的坐标偏差; $\sigma_{x} 、 \sigma_{y}$ 分别表示沿 $x$ 轴、 $y$ 轴 的标准差。中心表示地理要素在二维空间上分布 的相对位置, 方位角反映其分布的主趋势方向, 长 半轴表征地理要素在主趋势方向上的离散程度,短 半轴表示数据分布的范围。长短半轴的值差距越 大(扁率越大), 数据的方向性越明显, 短半轴越短, 数据呈现的向心力越明显; 反之, 表示数据的离散 程度越大。 


\subsection{2 地理探测器分析方法}

地理探测器用于探测属性 $y$ 及其解释因子 $x$ 的 空间分布是否一致。即对被解释变量空间分异与 因子空间分异的一致性检验,已广泛应用于地方性 疾病、城镇化、经济增长等方面(Wang et al, 2010; 丁 悦等, 2014)。本文采用地理探测器方法对人口老 龄化分布格局的影响因子进行分析,公式如下：

$$
P_{D H}=1-\frac{1}{n \sigma_{H}^{2}} \sum_{i=1}^{m}\left(n_{D, i} \times \sigma_{H_{D, i}}^{2}\right)
$$

式中: $P_{D H}$ 表示因素 $D$ 对人口老龄化程度 $H$ 的解释 力; $\sigma_{H}^{2}$ 为整个区域人口老龄化的离散方差; $n$ 为整 个研究区域内所有样本个数; $\sigma_{H_{D, i}}^{2}$ 为子区域 $i$ 人口 老龄化的离散方差; $n_{D, i}$ 为子区域 $i(i=1,2,3, \ldots, m)$ 内样本的个数。

\section{3 结果与分析}

\section{1 人口老龄化的空间分布特征}

根据联合国人口年龄结构类型的划分标准, 老 年人口比重在 $4.0 \%$ 以下的地区为人口年轻型地区; $4.0 \% \sim 7.0 \%$ 的地区为人口成年型地区; 超过 $7.0 \%$ 的 地区称为人口老年型地区。本文根据人口年龄结 构划分方法, 并结合林琳(2007)对人口老龄化衡量 标准的细化, 将人口年龄结构划分为 6 个类型, 即: 老年人口比重低于 $4.0 \%$ 称为年轻型 $(\mathrm{N}), 4.0 \% \sim 5.5 \%$ 之间的为成年型 $\mathrm{I}$ 期 $\left(\mathrm{C}_{1}\right), 5.5 \% \sim 7.0 \%$ 之间的称为成 年型 II 期 $\left(\mathrm{C}_{2}\right), 7.0 \% \sim 10.0 \%$ 之间为老年型 $\mathrm{I}$ 期 $\left(\mathrm{L}_{1}\right)$, $10.0 \% \sim 14.0 \%$ 之间称为老年型 $\mathrm{II}$ 期 $\left(\mathrm{L}_{2}\right)$, 老年人口比 重超过 $14.0 \%$ 称为老年型 III 期 $\left(\mathrm{L}_{3}\right)$ 。以 $2000 、 2010$ 年中国县域老年人口比重数据为基础, 参照以上标 准, 绘制人口老龄化的空间分布图(图 1-2)。从图中 可以发现人口老龄化的空间分布有以下特征:

(1) “胡焕庸线” 是人口老龄化的显著分界线。 图 1-2 显示, 年轻型人口与成年型人口区域主要位 于胡焕庸线西北半壁,老年型人口区域主要位于胡 焕庸线东南半壁。以 2010 年为例, 年轻型人口地区 共有 21 个, 其中 17 个位于胡焕庸线西北半壁, 仅有 4 个位于胡焕庸线东南半壁。相反, 人口老龄化大 于 $10 \%$ 的县有 620 个, 其中位于胡焕庸线东南半壁 的县域单元有 597 个, 仅有 23 个县域单元位于胡焕 庸线西北半壁。可以说, 胡焕庸线深刻地映射出中 国人口老龄化程度分布的区域差异。

(2) 人口老龄化空间分布模式多样。从毗邻区

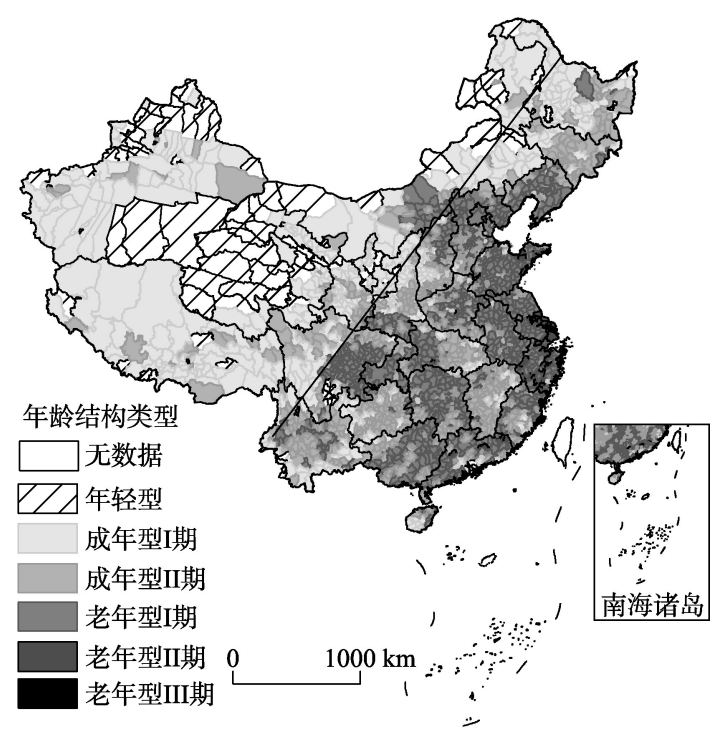

图 12000 年人口老龄化的空间分布

Fig.1 Spatial distribution of population ageing in 2000

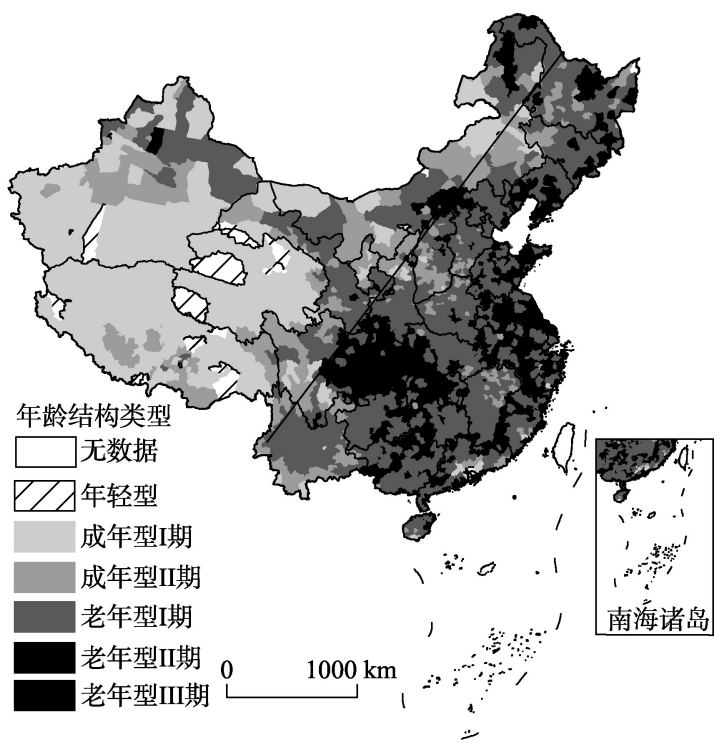

图2 2010年人口老龄化的空间分布

Fig.2 Spatial distribution of population ageing in 2010

域老龄化类型的空间组织特征考察, 可以将分布模 式概括为均质化 (即大范围老龄化类型基本一致, 以成年型 I 期为主)、带状(即毗邻区域老龄类型成年 型 III 期为主, 在空间上呈带状展布)、核心一外围 (中心区与外围区之间至少存在明显的老龄化类型 级差)等多种形式。

均质型区域往往分布在经济相对落后的边远 少数民族地区, 如西部地带的南疆、西藏、青海、内 蒙古西部、云南南部等区域,这些地区原有人口老 龄化水平低、出生率高, 基本以年轻型人口为主, 且 人口流动性不强, 10 年后人口类型虽然转变为成年 
型,但相较全国其他地区, 依然保持较低水平态势。 带状分布模式往往沿国家骨干路网集中分布, 由于骨干路网(主要是高速公路和国家干线铁路)沿 线城镇集中分布, 对人口迁移和经济拉动作用明 显,老龄化水平较高, 以成年型 III期为主。这类区 域以兰新铁路沿线最为典型。还有一类则主要出 现在省际接壤区, 尤其是以山地为界的省际接壤 区, 由于区位偏僻、自然环境恶劣、经济发育基础薄 弱, 人口生育普遍偏高, 年龄结构较轻, 流动性较 弱。如鄂渝湘边区同属武陵山区, 包括湘西苗族土 家族自治州、张家界、沅陵、怀化、恩施土家族苗族 自治州及渝东南的多个民族自治县, 少数民族约占 武陵山区总人口的 $48 \%$, 各地区文化相似, 交流密 切, 特殊的生育政策、生育观念和相似的生存环境 促成了人口老龄化的“均质”效应。

核心一外围模式往往出现在城镇(群) 区域, 又 可细分为两类: (1)高核心一低外围结构(即“隆升” 结构), 城市市辖区或城市群中心区老龄化水平高 于外围地区: 如兰西、哈大长和天山北坡城市群, 尤 以天山北坡城市群最典型, 2010 年老龄化水平呈现 出由核心向两侧递减的分布态势, 人口类型从老年 型 II 期逐渐向两边的成年型 II 期和 I 期过渡。人口 老龄化高值区域为石河子市、乌苏市、乌鲁木齐市 辖区, 被周边人口老龄化低值区域(乌鲁木齐县、和 静县、新源县)所包围, 构成了核心一外围的圈层分 布格局。2)低核心一高外围结构(即“塌缩”结构), 许多省(地)级市市辖区或城市群中心区老龄化水平 低于外围地区, 为塌缩型核心一外围结构模式, 如 安徽、浙江、湖南、四川等省, 其中安徽省最为典型; 城市群则以珠三角最为典型, 中心区以成年型 $I$ 期 为主, 而外围地区则呈现为老年型 II 期。

上述空间分布模式的形成与人口流动关联性
极强。如安徽人口老龄化程度最低的区域是合肥 市市辖区, 2010 年人口普查数据显示, 省内县际间 $81.79 \%$ 的流动人口流向了地级城市市辖区, 青壮年 人口的大量进人降低了人口老龄化的程度。而广 东省作为中国典型的发达地区, 其人口老龄化圈层 结构形成则主要归因于省外流动人口的大量流 人。2010年,珠三角的深圳、东莞、广州和佛山流动 人口总数达 2331.5 万人(刘涛等, 2015 )。大量青年 劳动力人口的流人使得核心区人口老龄化程度极 低、从沿海向内陆, 人口老龄化程度不断增大。

\section{2 人口老龄化的时空分布变化}

2000 年中国人口老龄化程度并不高, 2283 个县 老年人口比重均值为 $6.7 \%$ 。其中最大值为上海市 崇明县 $(13.8 \%)$, 最小值为深圳市市辖区 $(1.2 \%)$, 变 异系数为 0.245 。2000-2010年间,中国经历了快速 的人口老龄化, 2010 年 2283 个县老年人口比重均 值为 $8.7 \%$, 人口老龄化成为大部分县所面临的常 态。最大值为江苏省如东县 $(19.0 \%)$, 最小值仍为深 圳市市辖区 $(1.8 \%)$, 变异系数从 0.245 增加到 0.251 , 表明县域人口老龄化的相对差异有所扩大。

2000-2010年间, 2283 个县中, 年轻型人口地区 由 100 个下降为 21 个, 成年型人口地区由 1219 个剧 烈下降到 443 个, 而老年型人口地区由 964 个增加 到 1819 个,其中老年型 II 期县域数量从由 54 个猛 增至 600 个,充分说明中国人口老化不仅速度快,而 且程度深(表 1)。

10 年间共计 855 个县域单元步人了老年型(图 3)。 其中年轻型 $(\mathrm{N})$ 转变为老年型 $I$ 期 $\left(\mathrm{L}_{1}\right)$ 的县共计 12 个,除黑龙江省漠河县之外,其余县均位于兰新铁 路沿线,其中 6 个位于天山北坡城市群。成年型 I 期 $\left(\mathrm{C}_{1}\right)$ 转变为老年型 $I$ 期 $\left(\mathrm{L}_{1}\right)$ 的县共计 176 个, 主要 位于甘肃省河西走廊地带, 黑龙江省沿边地区。成

表 $12000-2010$ 年中国分县人口老龄化程度及其类型变化

Tab.1 Changes of degree and types of population ageing in China, 2000-2010

\begin{tabular}{|c|c|c|c|c|}
\hline \multirow{2}{*}{ 人口类型 } & \multicolumn{2}{|r|}{2000 年 } & \multicolumn{2}{|r|}{ 2010年 } \\
\hline & 县域数量 & 主要分布区 & 县域数量 & 主要分布区 \\
\hline 年轻型(N) & 100 & 中国北部边境线及甘、青、新交界处 & 21 & $\begin{array}{l}\text { 零星分布在西藏、青海、新疆及深圳、东莞等 } \\
\text { 区域 }\end{array}$ \\
\hline 成年型 I期( $\left.\mathrm{C}_{1}\right)$ & 470 & 胡焕庸线西北半壁及东北地区 & 149 & 胡焕庸线西北半壁、珠江三角洲核心区 \\
\hline 成年型 II期(C2) & 749 & 黄土高原、云贵高原、湖北、江西等区域 & 294 & 内蒙古、新疆等区域 \\
\hline 老年型 I期( $\left.\mathrm{L}_{1}\right)$ & 910 & 东部沿海与川渝地区 & 1199 & $\begin{array}{l}\text { 兰新铁路沿线、黄土高原、云贵高原、东北、江 } \\
\text { 西等区域 }\end{array}$ \\
\hline 老年型II期(L2) & 54 & 江浙地带 & 600 & 东部沿海与川渝地区 \\
\hline 老年型 III 期( $\left.\mathrm{L}_{3}\right)$ & 0 & 无 & 20 & 零散分布于江苏、四川等地区 \\
\hline
\end{tabular}


年型 $\mathrm{I}$ 期 $\left(\mathrm{C}_{1}\right)$ 转变为老年型 $\mathrm{II}$ 期 $\left(\mathrm{L}_{2}\right)$ 的县共 9 个, 零 星分布于新疆、内蒙古、黑龙江等地区。成年型 II 期 $\left(\mathrm{C}_{2}\right)$ 转变为老年型 $I$ 期 $\left(\mathrm{L}_{1}\right)$ 的县最多, 共 573 个研 究单元, 主要分布于云贵高原、江西、湖北、陕西关 中地区及吉林与黑龙江, 是转变为老年型区域的主 要地区。整体来看, 10 年间步人老年型的地区多集 中于内陆、东北、丝绸之路沿线地带。

应用标准差椭圆方法来刻画和描述 2000-2010 年中国县域人口老龄化总体空间分布变化(表 2 )。 从椭圆各项参数变化看: 2000-2010年间,椭圆的中 心坐标向西北方向移动, 表明高度人口老龄化区域 向西北方向有所扩散; 椭圆长轴增加了 $10.31 \mathrm{~km}$, 短轴增加了 $0.62 \mathrm{~km}$, 展布范围有所增加, 但增加值 较小, 表明人口老龄化高值区表现出轻微的空间分 散趋势; 椭圆的偏角从 $48.85^{\circ}$ 减为 $44.29^{\circ}$, 变化同样 较小, 表明人口老龄化空间分布始终呈东北一西南 走向。上述变化均表明, 中国人口老龄化出现了内 陆化的趋势, 其空间分布的集聚性有所减弱。

加权标准差椭圆显示方位角为 $44.29^{\circ}$, 而胡焕 庸线相对于正北方向的偏角约为 $45^{\circ}$, 两者十分接 近, 印证了“胡焕庸线”对人口老龄化空间分布的指 示作用。

为进一步刻画人口老龄化在特定方向上的变

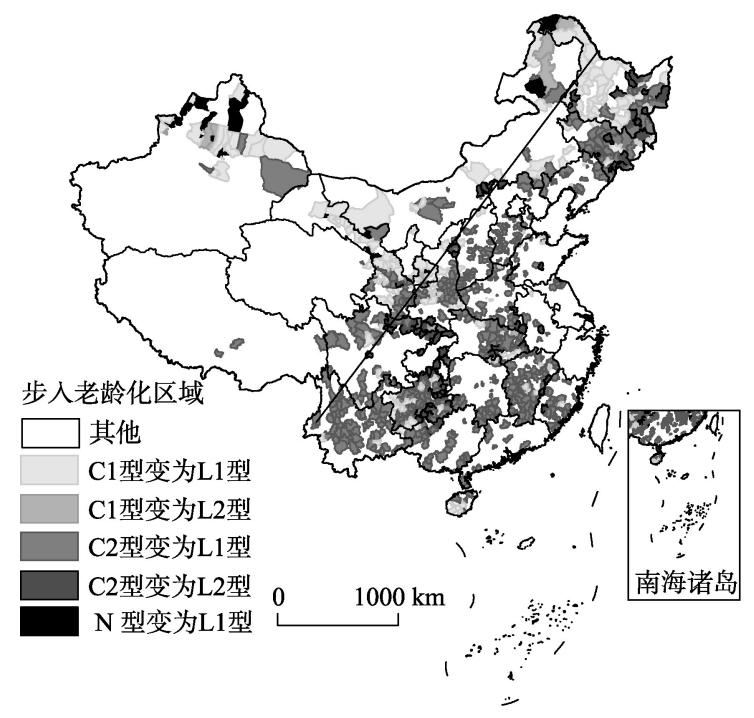

图 3 人口老龄化类型变化

Fig.3 Shifts of population ageing type in counties of China
化趋势, 采用趋势分析工具对中国县域人口老龄化 进行三维透视分析, 即将中国各县(市、区)的人口老 龄化系数作为 $Z$ 轴, 以 $X$ 正方向表示正东方向, 以 $Y$ 正方向表示正北方向,采用三次多项式拟合生成中 国县域人口老龄化的全局趋势面三维透视图,可准 确地揭示中国县域人口老龄化空间分布的总体格 局及特定方向的变化趋势(图 4)。由图 4 可见,2000 年东西方向上中国老龄化的变化趋势近似一条拉 平的 $\mathrm{S}$ 型曲线, 西部地区老龄化程度较低, 东中部地 区老龄化程度较高; 在南北方向上, 其变化趋势近 似一条扁形的倒U型曲线, 东北地区和东南沿海较 低, 北部沿海和东部沿海较高。2010年全局趋势发 生变化, 东西方向由 $\mathrm{S}$ 型转变为近似直线形态, 西北 内陆老龄化整体抬升, 南北方向上由倒 $U$ 型转变为 $\mathrm{S}$ 型, 其中较为显著的是东北地区老龄化的升高与 北部沿海地区的下降。

\section{3 人口老龄化速度的空间分异}

不同的区域,其人口转变所处的阶段不同。人 口老龄化速度也有所差异, 指数增长模式常被用于 模拟人口总体的变化过程。美国学者构建了测定 人口老龄化过程的新指标, 从动态角度度量人口老 龄化随时间的演化过程, 已得到了广泛应用(Rogers et al, 1992)。本文依据此方法测度县域人口老 龄化速度的空间分异(图 5)。

$T A_{i}(t)(65+)$ 为老年人口比重按指数模式的年均 增长率, 其计算公式为:

$$
\begin{aligned}
T A_{i}(65+) & =\frac{1}{n} \ln \left[\frac{p_{i}^{t+n}(65+)}{p_{i}^{t}(65+)}\right]-\frac{1}{n} \ln \left[\frac{p_{i}^{t+n}(0+)}{p_{i}^{t}(0+)}\right] \\
& =r_{i}(65+)-r_{i}(0+)
\end{aligned}
$$

式中: $p_{i}^{t}(65+) 、 p_{i}^{t}(0+)$ 分别为各县域单元老年人 口、总人口数; $p_{i}^{t+n}(65+) 、 p_{i}^{t+n}(0+)$ 分别为 $n$ 年后各 县域单元老年人口、总人口数; $r_{i}(65+) 、 r_{i}(0+)$ 分 别为各县域单元老年人口、总人口年均增长率。

近 10 年来, 中国县域人口老龄化速度有如下特 点(图 5): 一是人口老龄化速度存在显著的区域差 异。成渝地区、兰新铁路沿线、天山北坡地带、以及 东北地区人口老龄化速度较快, 其中最快的为内蒙 古区的根河市, 2000 年其老龄化程度仅为 $4.29 \%$,

表 2 人口老龄化标准差椭圆参数

Tab.2 Standard deviation ellipse parameters of population ageing

\begin{tabular}{ccccc}
\hline 年份 & 中心坐标 & 长半轴 $/ \mathrm{km}$ & 短半轴 $/ \mathrm{km}$ & 方位角 $/{ }^{\circ}$ \\
\hline 2000 & $111.81^{\circ} \mathrm{E}, 32.92^{\circ} \mathrm{N}$ & 1150.87 & 954.63 & 48.85 \\
2010 & $111.72^{\circ} \mathrm{E}, 33.07^{\circ} \mathrm{N}$ & 1161.18 & 955.25 & 44.29 \\
\hline
\end{tabular}


a. 2000 年

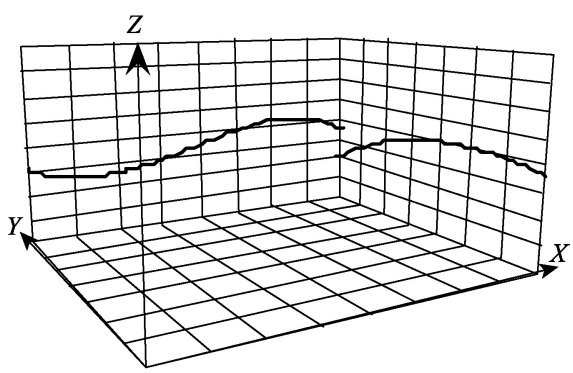

b. 2010 年

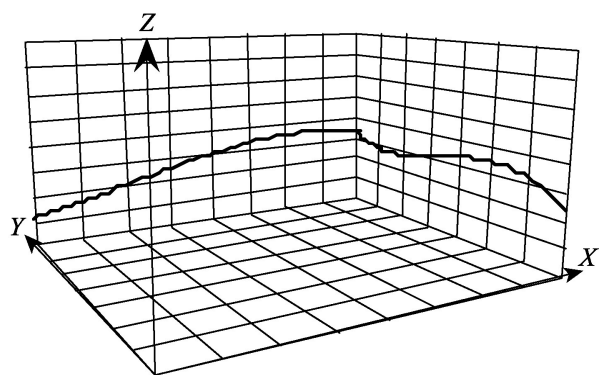

图 4 2000-2010年中国人口老龄化趋势分析图

Fig.4 China's ageing population trend, 2000-2010

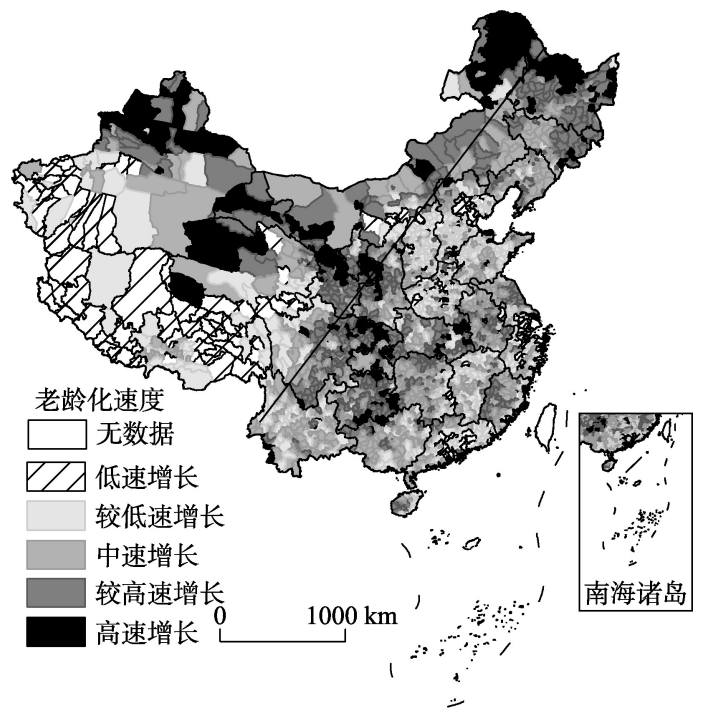

图 5 2000-2010年中国县域老年人口比重年均 增长率空间分布

Fig.5 Spatial distribution of annual growth rate of population ageing in counties of China, 2000-2010

2010 年快速增至 12.91\%(根河市统计公报显示, 2005-2010年其自然增长率连续 5 年为负增长)。而 西藏、南疆、华北地区、长三角、珠三角等地区人口 老龄化增长速度相对较慢。其中最慢的为江苏省 昆山市, 10 年间其人口老龄化程度从 $8.45 \%$ 降为 $5.53 \%$ 。二是人口老龄化负增长区域出现显著的两 极现象, 10 年间人口老龄化负增长县数共计 98 个, 其中位于西藏、新疆的县高达 34 个, 位于江苏、浙 江、广东、福建的为 34 个, 上海、天津 2 个直辖市均 出现了人口老龄化的负增长。三是市辖区人口老 龄化速度低于周围县域,特大城市表现得最为明 显, 如南京市市辖区人口老龄化速度仅为 $0.66 \%$ 。

\section{4 人口老龄化的区域差异}

\subsection{1 地域差异}

“胡焕庸线”不仅反映了中国人口空间分布的
区域差异性,尤为重要的是揭示了中国人口分布态 势与自然地理本底之间的高度空间耦合性和人地 关系状况(戚伟等, 2015)。“胡焕庸线”对人口老龄化 空间分布的指示作用是通过自然要素的组合体现 的。自然要素不同的区域人口老龄化是否存在显 著的差异性值得关注。谢高地等(2012)依据温度、 降水、海拔、植被及地貌类型,在保持县域单元完整 性的条件下,将中国划分为 11 类生态地区。本文基 于 11 类生态地区,以各生态地区内部县域为基本单 元, 对中国人口老龄化的区域差异作出分析(表 3)。

从 2 个时期方差大小看, 2000 年除长江中下游 与东北生态地区外,各类型区区内方差均小于全国 整体水平; 2010 年除长江中下游与内蒙古高原生态 地区外,均小于全国整体水平。可见,自然区划条 件下各区域内部人口老龄化存在一定的同质性, 区 域内部差距小于全国整体水平。从各类型区老龄 化程度看, 11 个类型区人口老龄化程度差异较大, 其中青藏高原高寒生态地区人口老龄化程度最低, 西北干旱、横断山区生态地区次之,三大区域均处 于人口成年型阶段。而内蒙古高原、黄土高原、云贵 高原生态地区人口老龄化程度均处于 $7.0 \%$ $8.0 \%$ 之 间,属于刚刚步人人口老年型阶段。2000年人口老 龄化程度最高的区域为长江中下游生态地区, 2010 年则为川渝生态地区。川渝地区快速的老龄化进 程值得关注。从人口老龄化的空间分布来看, 相对 于传统的东、中、西三大地区间的差异比较, 基于自 然区划的人口老龄化区域差异更为明晰。

\subsection{2 城乡差异}

长期以来, 中国存在着城乡二元结构。城乡间 经济发展水平、医疗卫生条件、社会保障制度存在 显著差异。一方面,城市地区实施了更为严格的计 划生育政策, 加之生育观念的转变,使得城市地区 生育率水平快速下降; 另一方面, 城市地区生活水 
平较高, 医疗卫生设施完善, 人均预期寿命较长。 因此, 城市地区人口老龄化程度长期高于乡村地 区。近年来, 伴随着城镇化进程的不断推进, 大量 流动人口进人城市地区, 在流动人口偏年轻化的背 景下,城乡间人口老龄化程度发生了变化(表 4)。可 以发现, 2000 年农村人口老龄化程度高于城镇地区 $1.08 \%$ 。2000-2010年,中国城镇化水平从 $36.91 \%$ 增 加到 $50.27 \%$, 而农村人口老龄化程度已高于城镇地 区 $2.26 \%$, 城乡间人口老龄化的差异进一步扩大。 2000-2010 年中心城区老龄人口占总老龄人口的比 例增加了 $3.03 \%$, 同时中心城区总人口占全国总人 口的比例增加了 $4.53 \%$, 总人口增加速度超过了老 龄人口。中心城区老龄化程度仅增加 $1.38 \%$,而县 域人口老龄化程度增加 $2.04 \%$ 。可见, 县域的老龄 化速度更快。

\subsection{3 民族自治区域与非民族自治区}

根据中国国家民族事务委员会公布的民族自 治地方名单, 对县域进行分类, 分析民族自治地方
与非民族自治地方老龄化的区域差异(表 5)。

一般而言，民族自治地方得益于其特殊的生育 政策,生育率高于其他地方, 长时期较高的生育率 使得其老龄化程度较低。2000 年其老龄化程度为 $6.14 \%$,低于非民族地区 $1.09 \%$ 。2010年民族地区 虽整体进人了老龄化社会,老龄化程度仍低于非民 族地区 $0.86 \%$ 。其老龄化速度快于非民族地区,老 龄人口所占比例不变的情况下, 总人口所占比例减 少是其老龄化加快的直接原因。

\subsection{4 贫困与非贫困地区}

根据国务院扶贫开发领导小组公布的中国贫 困县名单, 分别统计中国贫困县与非贫困县人口的 老龄化程度进行分析(表 6)。

从表 6 可以发现,2000-2010年间,贫困地区老 龄人口所占比重变化不大。与此同时,贫困地区总 人口所占比重下降 $1.5 \%$ 。2000 年其老龄化程度为 $6.41 \%$,低于非贫困地区 $0.84 \% ; 2010$ 年贫困地区老 龄化程度低于非贫困地区 $0.17 \%$ 。贫困地区的老龄

表 311 类生态地区间人口老龄化程度比较分析

Tab.3 Comparison of aged population in 11 ecoregions

\begin{tabular}{|c|c|c|c|c|c|c|}
\hline \multirow{2}{*}{ 生态地区 } & \multicolumn{2}{|c|}{ 老年人口数/万 } & \multicolumn{2}{|c|}{ 老龄化程度/\% } & \multicolumn{2}{|c|}{ 方差 } \\
\hline & 2000年 & 2010年 & 2000年 & 2010年 & 2000 年 & 2010年 \\
\hline 东北生态地区 & 914.2 & 1317.2 & 6.76 & 8.85 & 0.0179 & 0.0218 \\
\hline 华北生态地区 & 2033.5 & 2558.4 & 7.56 & 9.12 & 0.0118 & 0.0155 \\
\hline 内蒙古高原生态地区 & 109.1 & 165.3 & 5.86 & 7.71 & 0.0155 & 0.0235 \\
\hline 西北干旱生态地区 & 115.4 & 189.5 & 4.70 & 6.78 & 0.0089 & 0.0175 \\
\hline 黄土高原生态地区 & 499.7 & 707.7 & 5.90 & 7.92 & 0.0127 & 0.0162 \\
\hline 川渝生态地区 & 1218.9 & 1680.6 & 7.56 & 10.67 & 0.0122 & 0.0197 \\
\hline 长江中下游生态地区 & 1660.5 & 2227.4 & 8.06 & 9.90 & 0.0209 & 0.0237 \\
\hline 华南生态地区 & 1804.6 & 2383.0 & 6.88 & 8.04 & 0.0154 & 0.0204 \\
\hline 云贵高原生态地区 & 423.8 & 598.5 & 5.94 & 7.95 & 0.0116 & 0.0144 \\
\hline 青藏高原高寒生态地区 & 20.0 & 28.2 & 3.65 & 5.25 & 0.0094 & 0.0110 \\
\hline 横断山区生态地区 & 27.8 & 37.0 & 5.70 & 6.86 & 0.0077 & 0.0125 \\
\hline 全国 & 8827.4 & 11892.7 & 7.10 & 8.92 & 0.0176 & 0.0225 \\
\hline
\end{tabular}

表 4 中国城镇与乡村地区人口老龄化程度比较

Tab.4 Comparison of aged population in urban and rural areas

\begin{tabular}{|c|c|c|c|c|c|c|}
\hline 年份 & 分类 & 总人口/万 & 占全国比重 $/ \%$ & 老龄人口/万 & 占全国比重/\% & 老龄化程度/\% \\
\hline \multirow[t]{2}{*}{2000} & 城镇 & 45877.10 & 36.91 & 2946.52 & 24.78 & 6.42 \\
\hline & 乡村 & 78384.12 & 63.08 & 5880.88 & 66.62 & 7.50 \\
\hline \multirow[t]{2}{*}{2010} & 城镇 & 67000.55 & 50.27 & 5225.42 & 43.94 & 7.80 \\
\hline & 乡村 & 66280.53 & 49.73 & 6667.29 & 56.06 & 10.06 \\
\hline \multirow[t]{2}{*}{2000} & 城区 & 33426.36 & 26.90 & 2310.55 & 26.17 & 6.91 \\
\hline & 县域 & 90834.87 & 73.10 & 6516.85 & 73.83 & 7.17 \\
\hline \multirow[t]{2}{*}{2010} & 城区 & 41887.05 & 31.43 & 3472.98 & 29.20 & 8.29 \\
\hline & 县域 & 91389.32 & 68.57 & 8419.72 & 70.80 & 9.21 \\
\hline
\end{tabular}


化进程加快, 与民族地区类似, 在老龄人口所占比 例不变的情况下, 总人口所占比例减少是其老龄化 加速发展的直接原因。

\section{5 人口老龄化原因分析}

长期以来, 对影响区域人口数量与结构的研究 通常从“人口自身”和“社会经济因素” 2 个方面进行 分析(于涛方, 2013)。一般而言, 人口的生育率、人 均预期寿命与期初人口年龄结构是影响人口老龄 化的主要因素(杜鹏, 1992)。人口老龄化是一个长 期的过程, 从时序变化来看, 人口惯性对人口老龄 化的贡献率最高(曲海波, 1989)。在流动人口规模 日益扩大的趋势下, 人口流动对老龄化的影响日益 增强(张航空, 2015)。除人口学方面的原因外, 人口 老龄化同时也受多种因素的综合影响,如区域养老 设施与生活成本、区域自然条件等。如于涛方 (2013)认为, 老龄化人口在空间上的流动活跃性较 低, 人口老龄化的空间分布与区域社会经济因素密 切相关。据此, 选取以下变量进行分析 : (1)被探测 因子: 将 2010 年人口老龄化程度作为被探测因子。 (2)自然因素: 以 11 类生态区划为基础,纳人地理探 测器, 探索自然要素的组合对人口老龄化程度的影 响。3人口因素: 采用 2000 年各地区 55 65 岁人口 占总人口的比例作为人口年龄结构变动因素, 其比 例越高, 10 年后对人口老龄化程度的影响就越大。
由于无法获取县域尺度的生育率数据, 引人 15 64 岁妇女平均子女存活数作为生育率的代替变量。 参考刘涛等(2015)的研究,采用流动人口数与户籍 人口数的比值作为衡量流人人口的代替变量。将 流人人口与净迁移人口之差与户籍人口数的比值 作为流出人口的代替变量。同时人口老龄化与期 初人口老龄化程度极为密切, 因此将 2000 年人口老 龄化程度纳人分析。(4)社会经济因素: 经济的增 长、医疗卫生条件的改善和文化水平的提高等社会 经济因素均会对人口老龄化产生间接影响。选择 人均 GDP、每千人拥有病床数、人均受教育年限作 为区域经济增长、医疗卫生条件、文化水平的代替 变量。

分别对各个指标变量进行自然断点分级聚类, 采用地理探测器分析方法, 得出各影响因素对人口 老龄化程度动态变化的决定力 $P$ 值及其显著性水 平。决定力的大小表明了变量的空间分布与 2010 年人口老龄化空间分布的一致性程度。

由表 7 可以发现: 所有变量均通过了 $5 \%$ 的显著 性水平检验, 表明上述因素对人口老龄化均具有显 著的决定力。从决定力的大小方面来看: (1)人口老 龄化的首要决定因子为 2000 年的人口老龄化程度, 决定力达 0.63 。次要决定因子为 2000 年各地区 55 65 岁人口占总人口的比例, 可见各区域自身人口年

表 5 中国民族自治地区与非民族自治地区人口老龄化程度比较

Tab.5 Comparison of aged population in ethnic minority autonomous regions and other regions

\begin{tabular}{clrcrrr}
\hline 时间 & \multicolumn{1}{c}{ 分类 } & 总人口/万 & 占全国比重 $/ \%$ & 老龄人口/万 & 占全国比重 $/ \%$ & 老龄化程度/\% \\
\hline \multirow{2}{*}{2000 年 } & 民族自治区 & 14212.04 & 11.44 & 872.53 & 9.88 & 6.14 \\
& 非自治区 & 110049.18 & 88.56 & 7954.87 & 90.12 & 7.23 \\
2010 年 & 民族自治区 & 14393.26 & 10.80 & 1174.76 & 9.88 & 8.16 \\
& 非自治区 & 118883.11 & 89.20 & 10717.93 & 90.12 & 9.02 \\
\hline
\end{tabular}

表 6 中国贫困县与非贫困县老年人口系数比较

Tab.6 Comparison of aged population in poverty counties and non-poverty counties

\begin{tabular}{ccrcccc}
\hline 时间 & 分类 & 总人口/万 & 占全国比重/\% & 老龄人口/万 & 占全国比重 $/ \%$ & 老龄化程度 $/ \%$ \\
\hline \multirow{2}{*}{2000 年 } & 贫困地区 & 21586.56 & 17.37 & 1383.06 & 15.67 & 6.41 \\
& 非贫困区 & 102674.67 & 82.63 & 7444.34 & 84.33 & 7.25 \\
2010 年 & 贫困地区 & 21153.35 & 15.87 & 1856.75 & 15.61 & 8.78 \\
& 非贫困区 & 112123.02 & 84.13 & 10035.95 & 84.39 & 8.95 \\
\hline
\end{tabular}

表 7 各影响因素对县域人口老龄化变化量的决定力地理探测结果

Tab.7 Influencing factors for county-level change of population ageing by geographic detector analysis

\begin{tabular}{cccccccccc}
\hline & $\begin{array}{c}2000 \text { 年老龄化 } \\
\text { 程度 }\end{array}$ & $\begin{array}{c}10 \text { 年间步人老年 } \\
\text { 人口比重 }\end{array}$ & $\begin{array}{c}\text { 平均存活子 } \\
\text { 女数 }\end{array}$ & $\begin{array}{c}\text { 流人人口占常住 } \\
\text { 人口比例 }\end{array}$ & $\begin{array}{c}\text { 流出人口占户 } \\
\text { 籍人口比例 }\end{array}$ & $\begin{array}{c}\text { 自然 } \\
\text { 区划 }\end{array}$ & $\begin{array}{c}\text { 人均 } \\
\text { GDP }\end{array}$ & $\begin{array}{c}\text { 人均床 } \\
\text { 位数 }\end{array}$ & $\begin{array}{c}\text { 人均受教育 } \\
\text { 年限 }\end{array}$ \\
\hline 决定力 & 0.63 & 0.51 & 0.01 & 0.04 & 0.16 & 0.37 & 0.02 & 0.02 & 0.14 \\
显著性水平 & 0.00 & 0.00 & 0.01 & 0.00 & 0.00 & 0.00 & 0.04 & 0.00 & 0.00 \\
\hline
\end{tabular}


龄结构的更替是影响当前人口老龄化程度的决定 因素,受各区域历史时期经济与文化背景的影响， 不同区域的人口年龄结构有较大差异,不同的人口 年龄结构对区域人口老龄化的影响不仅具有现时 性,也具有一定的时滞性。2区域自然条件是决定 人口老龄化程度的第三大决定因子。适中的海拔 高度、适宜的气候条件、良好的水质、食物中含有的 微量元素等多种自然要素均会影响人类健康, 区域 自然条件对人口的预期寿命有很大的影响, 从而影 响区域的人口老龄化程度。(3)流出人口比例对人 口老龄化程度的影响较高。10年来, 中国经历了快 速的城镇化进程, 人口流动性大大增强, 大量人口 流出改变了流人区与流出区的人口年龄结构, 在流 动人口年龄结构年轻化背景下, 流出区域人口老龄 化速度大大加快, 使得流出人口比例对区域人口老 龄化具有较大的决定力。(4)受教育程度的高低影 响人口老龄化程度。受教育水平越高, 生育观念及 生育行为发生改变, 生育率降低, 影响人口老龄化。

从 4 类不同类型的影响因子来看: (1)社会经济 因素对人口老龄化的决定力较低。其中人均 GDP、 医疗卫生条件的决定力均为 0.02 。2 010 年中国人 均预期寿命已达 74.83 周岁, 远超过老龄人口 65 周 岁的标准。社会经济因素对人口老龄化的影响具 有阶段性, 随着生活质量的不断提高, 社会经济因 素对人口生育、寿命的限制趋于稳定。此外, 经济 发达的地区吸引了大量的流动人口, 使其人口老龄 化程度往往极低。这表明社会经济的空间分布与 人口老龄化空间分布并不一致。(2)口年龄结构 的代替变量对人口老龄化的影响较强, 从本质上 讲, 人口年龄结构的惯性表现是造成人口老龄化的 一个重要原因, 但人口年龄结构实际上是前一个时 期生育率和死亡率作用的结果。此外, 人口流出比 例对人口老龄化的影响较强。除人口自身更替与 流出人口外, 近期生育率与流人人口对老龄化变化 的决定力较小, 长期的低生育水平才是造成人口年 龄结构转变的重要因素。(3)在宏观角度来看, 自然 地理环境的空气、水源、气候及植被等对人口老龄 化的空间分布有很强的制约作用。

\section{4 结论与建议}

从县域尺度出发, 可以清晰刻画和展现中国人 口老龄化空间格局的细节特征与规律, 基于 2000 和 2010 年人口普查数据, 采用标准差椭圆、地理探测
器等方法,测度了 2000-2010 年县域人口老龄化的 空间分布及其影响因素。结果表明:

(1) 人口老龄化空间分布模式呈现多样化的特 点。在青藏高寒区, 分布呈现均质化的特点; 在丝 绸之路沿线,人口老龄化分布呈现带状特征; 在珠 江三角洲地区还表现出临海一内陆圈层式分布; 在 安徽等地区呈现出中心一外围等多种分布模式。

(2) 10 年间,在县域尺度上, 中国整体步人了老 年型社会, 步人老年型的地区多集中于内陆、东北、 丝绸之路沿线地带, 人口老龄化总体空间格局变化 不大。

(3) 人口老龄化程度存在显著的区域差异，“胡 焕庸线” 是人口老龄化的基本分界线。不同地区 间、城乡间差异呈扩大的趋势, 而民族自治地区与 非民族自治地区、贫困地区与非贫困地区，人口老 龄化的差异呈缩小的趋势。

(4) 决定人口老龄化程度各因子的重要程度依 次为: 往期人口老龄化程度、各区域自身人口年龄 结构的更替、不同的自然环境、人口流出比例、人均 受教育年限。同时发现,社会经济因素,短期的生 育率水平对人口老龄化的决定力较低。这是因为 短期生育政策对老龄化的影响是无法立即显现 的。从全国来看, 总和生育率仅为 1.18 (发达国家约 为 1.60$)$, 最低的北京仅 0.71 , 最高的广西也仅为 1.79 , 都低于人口更替水平(2.10)。长期计划生育促 使中国老龄化加快, 养老问题日趋严峻。以中国目 前的老龄化程度和低生育率, 未来中国或许面临更 严重的老龄化。尽管 2013 年中国开始放开“单独二 孩”,但政策实践结果表明,人们的生育意愿很低。 2015年实施“全面二孩”政策,据国家卫生计生委测 算, 到 2030 年左右,该政策对老龄化的程度将缓解 两个百分点左右, 将逐渐减缓老龄化进程。

乡村地区、民族自治地区、贫困地区人口老龄 化的进程加快, 对当地经济发展、社会稳定提出了 严峻的挑战。针对乡村地区、民族自治地区、贫困 地区创新养老模式, 完善养老的制度保障尤为重 要。此外, 西北干旱区、青藏高原高寒生态地区、横 断山区即将步人老年型社会, 应针对人口结构变化 态势超前思考,未雨绸缪。

10 年间决定人口老龄化程度的一个重要因素 是人口流出比例。流出人口既对人口流人区域老 龄化产生影响,也对人口流出区域产生影响。中国 流动人口发展报告指出, 流动人口在现居住地居住 3 年及以上的占 $55 \%$, 居住 5 年及以上的占 $37 \%$, 半 
数以上流动人口有今后在现居住地长期居留的意 愿。随着时间的推移, 流动人口步人老年, 人口流 人区域面临的老龄化形势可能更为严峻,因此人口 流人与人口流出区域的人口老龄化预警需及早引 起重视,应对策略应具有一定的前瞻性。

\section{参考文献(References)}

柴彦威, 田原裕子, 李昌霞. 2006. 老年人居住迁移的地理学 研究进展 [J]. 地域研究与开发, 25(3): 109-115. [Chai Y W, Tahara Y, Li C X. 2006. A review of the geographical research on the elderly migration[J]. Areal Research and Development, 25(3): 109-115.]

丁悦, 蔡建明, 任周鹏, 等. 2014. 基于地理探测器的国家级 经济技术开发区经济增长率空间分异及影响因素 [J]. 地 理科学进展, 33(5): 657-666. [Ding Y, Cai J M, Ren Z P, et al. 2014. Spatial disparities of economic growth rate of China's National- level ETDZs and their determinants based on geographical detector analysis[J]. Progress in Geography, 33(5): 657-666.]

杜鹏. 1992. 中国人口老龄化主要影响因素的量化分析 [J]. 中国人口科学, (6): 18-24. [Du P. 1992. Zhongguo renkou laolinghua zhuyao yingxiang yinsu de lianghua fenxi[J]. Population Science of China, (6): 18-24.]

高晓路, 吴丹贤, 许泽宁, 等. 2015. 中国老龄化地理学综述 和研究框架构建 [J]. 地理科学进展, 34(12): 1480-1494. [Gao X L, Wu D X, Xu Z N, et al. 2015. A review and frame- work setting of geographical research on aging in China[J]. Progress in Geography, 34(12): 1480-1494.]

李日邦, 王五一, 谭见安, 等. 1999. 我国人口老龄化发展的 阶段、趋势和区域差异 [J]. 地理研究, 18(2): 113-121. [Li R B, Wang W Y, Tan J A, et al. 1999. The development stages and trend of population ageing and its regional differences in China[J]. Geographical Research, 18(2): 113121.]

李扬, 刘慧, 金风君, 等. 2011. 北京市人口老龄化的时空变 化特征 [J]. 中国人口-资源与环境, 21(11): 131-138. [Li Y, Liu H, Jin F J, et al. 2011. Spatiotemporal transition of the aging population based on ESDA-GIS in Beijing City [J]. China Population, Resources and Environment, 21 (11): 131-138.]

林琳, 马飞. 2007. 广州市人口老龄化的空间分布及趋势 [J]. 地理研究, 26(5): 1043-1054. [Lin L, Ma F. 2007. Spatial distribution and trends of the aging of population in Guangzhou[J]. Geographical Research, 26(5): 1043-1054.]

刘华军, 何礼伟, 杨骞. 2014. 中国人口老龄化的空间非均衡 及分布动态演进: 1989-2011[J]. 人口研究, 38(2): 71-82. [Liu H J, He L W, Yang Q. 2014. Spatial inequality and distributional dynamics of population ageing in China, 19892011[J]. Population Research, 38(2): 71-82.]
刘涛, 齐元静, 曹广忠. 2015. 中国流动人口空间格局演变机 制及城镇化效应: 基于 2000 和 2010 年人口普查分县数 据的分析 [J]. 地理学报, 70(4): 567-581. [Liu T, Qi Y J, Cao G Z. 2015. China's floating population in the 21 st century: Uneven landscape, influencing factors, and effects on urbanization[J]. Acta Geographica Sinica, 70(4): 567-581.] 戚伟, 刘盛和, 赵美风. 2015. “胡焕庸线”的稳定性及其两侧 人口集疏模式差异 [J]. 地理学报, 70(4): 551-566. [Qi W, Liu S H, Zhao M F. 2015. Study on the stability of Hu Line and different spatial patterns of population growth on its both sides[J]. Acta Geographica Sinica, 70(4): 551-566.] 曲海波. 1989. 中国人口老龄化的人口学原因 $[\mathrm{J}]$. 人口研究, (4): 8-16. [Qu H B. 1989. Zhongguo renkou laolinghua de renkouxue yuanyin[J]. Population Research, (4): 8-16.]

单良, 丁莉. 2013. 中日人口老龄化的空间分布特征比较研 究 [J]. 中国人口科学, (4): 89-96. [Shan L, Ding L. 2013. Comparative research on the feature of spatial distribution of aging population between China and Japan[J]. Chinese Journal of Population Science, (4): 89-96.]

王志宝, 孙铁山, 张杰斐. 2015 . 人口老龄化区域类型划分与 区域演变分析: 以中美日韩四国为例 [J]. 地理科学, 35 (7): 822-830. [Wang Z B, Sun T S, Zhang J F. 2015. Regional types' division of population aging and analysis on population aging regional evolution: Based on China, America, Japan and R O Korea[J]. Scientia Geographica Sinica, 35(7): 822-830.]

谢安. 2004. 中国人口老龄化的现状、变化趋势及特点 [J]. 统 计研究, (8): 50-53. [Xie A. 2004. China population ageing: The current situation, prospect and characteristics[J]. Statistical Research, (8): 50-53.]

谢高地, 张昌顺, 张林波, 等. 2012. 保持县域边界完整性的 中国生态区划方案 [J]. 自然资源学报, 27(1): 154-162. [Xie G D, Zhang C S, Zhang L B, et al. 2012. China's county-scale ecological regionalization[J]. Journal of Natural Resources, 27(1): 154-162.]

于涛方. 2013. 中国城市老龄化空间特征及相关因素分析: 基于 “五普”和 “六普” 人口数据的分析 [J]. 城市规划学 刊, (6): 58-66. [Yu T F. 2013. Zhongguo chengshi laolinghua kongjian tezheng ji xiangguan yinsu fenxi: Jiyu "Wupu" he "Liupu" renkou shuju de fenxi[J]. Urban Planning Forum, (6): 58-66.]

袁俊, 吴殿廷, 吴铮争. 2007. 中国农村人口老龄化的空间差 异及其影响因素分析[J]. 中国人口科学, (3): 41-47. [Yuan J, Wu D T, Wu Z Z. 2007. Analysis on regional disparity and contributing factors of rural population aging in China[J]. Chinese Journal of Population Science, (3): 41-47.]

张航空. 2015. 人口流动对中国不同省份人口老龄化的影响 [J]. 人口学刊, 37(1): 95-102. [Zhang H K. 2015. The influence of population floating on the region aging of China [J]. Population Journal, 37(1): 95-102.] 
张开洲, 陈楠. 2014. 1990-2010 年福建省县域人口老龄化时 空演变特征及其驱动机制 [J]. 地理科学进展, 33(5): 605615. [Zhang K Z, Chen N. 2014. Characteristics of spatialtemporal evolution in population aging and driving mechanism at county level in Fujian Province during 1990-2010 [J]. Progress in Geography, 33(5): 605-615.]

赵作权. 2009. 地理空间分布整体统计研究进展 [J]. 地理科 学进展, 28(1): 1-8. [Zhao Z Q. 2009. Global statistics of spatial distribution: A literature review[J]. Progress in Geography, 28(1): 1-8.]

National Research Council (NRC). 2011. 理解正在变化的星 球: 地理科学的战略方向 [M]. 刘毅, 刘卫东, 译. 北京: 科 学出版社. [National Research Council (NRC). 2011. Understanding the changing planet: Strategic directions for the geographical sciences[M]. Liu Y, Liu W D, Trans.. Beijing, China: Science Press.]

Káčerová M, Ondačková J, Mladek J. 2012. A comparison of population ageing in the Czech Republic and the Slovak Republic based on generation support and exchange[J]. Moravian Geographical Reports, 20(4): 26-38.

McCarthy K F. 1983. The elderly population's changing spatial distribution: Patterns of change since 1960[M]. Santa Monica, CA: Rand Corporation.

Rogers A, Woodward J A. 1992. Tempos of elderly age and geographical concentration[J]. The Professional Geographer, 44(1): 72-83.

Wang J F, Li X H, Christakos G, et al. 2010. Geographical detectors-based health risk assessment and its application in the neural tube defects study of the Heshun region, China [J]. International Journal of Geographical Information Science, 24(1): 107-127.

Yuill R S. 1971. The standard deviational ellipse: An updated tool for spatial description[J]. Geografiska Annaler: Human Geography, 53(1): 28-39.

\title{
Spatial patterns and regional differences of population ageing in China based on the county scale
}

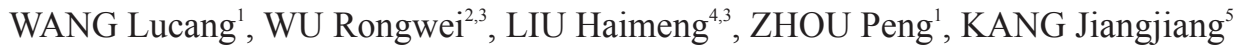 \\ (1. College of Geography and Environment Science, Northwest Normal University, Lanzhou 730070, China; \\ 2. Xinjiang Institute of Ecology and Geography, CAS, Urumqi 830011, China; 3. University of Chinese Academy \\ of Sciences, Beijing 100049, China; 4. Institute of Geographic Sciences and Natural Resources Research, CAS, \\ Beijing 100101, China; 5. College of Environment and Planning, Henan University, Kaifeng 475004, Henan, China)
}

\begin{abstract}
Population ageing is becoming one of the major challenges that cannot be overlooked in the process of socioeconomic development in china. China has entered into the ageing society since 2000. Based on the county-scale data in the 2000 and 2010 censuses and using standard deviational ellipse (SDE) and geographical detector methods, this study systematically analyzed the spatial distribution characteristics and regional differences of population ageing. The results are as follows: First, Population ageing varies spatially. Population ageing on the Qinghai-Tibet Plateau usually shows an even distribution. Population ageing on the southeastern side of China usually shows a center-periphery type of distribution and coastal-inland contrast. Second, the mean value of aged population proportion increased from 6.7\% to 8.0\% between 2000 and 2010. By 2010, China had become an aged society. The counties that had high percentage of aged population concentrated in the interior, the Northeast, and along the silk road economic region. The spatial pattern of population ageing is relatively stable, but significant difference was found in the trend of population ageing change. Third, there are regional differences in the population ageing of China, characterized by differences between urban areas and the countryside, ethnic minority regions and other regions, and poverty-stricken region and non-poverty areas. But the direction of change is not consistent. Last, There are many factors affecting population ageing level of counties, mainly including population ageing of the year 2000, population age structure, natural conditions, emigration rate, and economic development stage. The distribution of social and economic development level was not consistent with the distribution of population ageing change.
\end{abstract}

Key words: population ageing; county scale; spatial pattern; regional differences; China 